\title{
An invisible hand has guided clinical endocrinology toward an unexpected future
}

\author{
F. Trimarchi ${ }^{1}$
}

Received: 7 April 2020 / Accepted: 10 April 2020 / Published online: 20 April 2020

(C) Italian Society of Endocrinology (SIE) 2020

\section{Dear Editor,}

When in 2015 I published in the Journal of Endocrinological Investigation an Opinion dealing with my reflections on the near future of clinical endocrinology [1], I never imagined what the future would be only 5 years later. In the spring of 2020, the endocrinologists suddenly had to face a largely unknown way to follow their patients, collect their complaints, adjust drug dose, suggest behavior and lifestyle, and suggest tests by a phone call or a video call. This scenario relates to continuity of care and relationship between a doctor and a patient who are aware of the current health problem and is adequately organized with regard to the care of diabetic patients also in Italy, based on the recommendations of national scientific societies (https://societaitalianadiendocrin ologia.it/html/cnt/emergenza-covid.asp) with recent reports on the impact of SARS-Cov-2 on diabetes [2].

But what happens in telemedicine if the endocrine problem is known neither to the doctor nor to the patient, or in the infrequent event of an endocrine emergency? The latter requires physical contact in an adequately protected environment and includes adrenal crisis, hyponatremia, hypocalcemia and acute hypercalcemia, pituitary apoplexy, severe thyrotoxicosis, acute complications during therapy for severe Graves' orbitopathy, and advanced thyroid cancer in progression. However, the majority of patients already diagnosed with and treated for an endocrine disorder can adequately benefit from a relationship with the specialist through the tool of telemedicine.

This new way of being a doctor implies a substantial change of perspective that has been recently outlined by Kittleson [3]. Kittleson reported that on 3 March 2020, she visited a 70 -year-old man with a typical history of stable

F. Trimarchi

francesco.trimarchi@unime.it

1 Accademia Peloritana dei Pericolanti, University of Messina, Messina, Italy angina, and according to international guidelines prescribed beta blockers, aspirin and a statin, temporarily ruling out the need for a coronary angiography despite the disappointment of the patient and his wife who were very afraid "of a ticking time bomb in the chest". Two weeks later, despite the cardiologist's concern (I have to look him in the face, I have to auscult to the heart sounds), the visit took place by phone, with a complete change of perspective: if before Covid-19 the cardiologist had to weigh the cost/benefit ratio of a coronary angiography and reconcile it with the fear of the procedure standard risk, from 16 March the fear of a possible fatal respiratory disease was added. The "time bomb" had now become Covid-19, and the patient and his wife no longer claimed coronary angiography because the patient was "ill" with Covid-19, not because the virus had penetrated his lungs but because it had filled him with fear. Thus, the invisible hand of Covid-19 had relieved the doctor from the commitment to reconcile adherence to GLs with the patient's requests, with an unexpected change of perspective. But, concluded Kittleson: "Overwhelmed by the anticipated harms of Covid-19, we must remember that other diseases will continue to progress during the pandemic".

The endocrinologist must therefore learn to cope, especially in the setting of online diagnosis and treatment, not only with the effects of the disease on the patient's health, but also his/her fears, in an unexpected and unpredictable scenario. But once the world hopefully returns to "normality", clinical endocrinology should try and preserve, as much as possible, the clinical approach that involves direct physical and visual contact and verbal communication.

\section{Compliance with ethical standards}

Conflict of interest Author declares that he has no conflicts of interest.

Ethical approval This article does not contain any studies with animals performed by the author. 
Informed consent Informed consent is not required for this study.

\section{References}

1. Trimarchi F (2015) Clinical endocrinology in the near future: a post-modern challenge. J Endocrinol Invest 38(1):95-99. https:// doi.org/10.1007/s40618-014-0181-7

2. Fadini GP, Morieri ML, Longato E, Avogaro A (2020) Prevalence and impact of diabetes among people infected with SARS-CoV-2. J Endocrinol Invest. https://doi.org/10.1007/s40618-020-01236-2
3. Kittleson MM (2020) The invisible hand-medical care during the pandemic. New Engl J Med. https://doi.org/10.1056/NEJMp 2006607

Publisher's Note Springer Nature remains neutral with regard to jurisdictional claims in published maps and institutional affiliations. 